\title{
Portal Rede Mulheres Empreendedoras: empreendedorismo, cultura e imagens de si
}

\author{
Women Entrepreneurs Network's Website: entrepreneurship, culture and self-images
}

\author{
Eliane Davila dos Santos ${ }^{1}$ \\ Gislene Feiten Haubrich² \\ 1,2 Universidade Feevale, Novo Hamburgo, Rio Grande do Sul, Brasil.
}

$\diamond$

\begin{abstract}
Resumo: O artigo trata da temática do empreendedorismo, em especial do ethos da mulher empreendedora. Tem como objetivo analisar a representação do empreendedorismo feminino e identificar os aspectos culturais que se manifestam nas cenas enunciativas e no ethos discursivo em materialidades discursivas divulgadas no Portal Rede Mulheres Empreendedoras. A análise discursiva está fundamentada na proposta de Maingueneau (1997, 2008a, b, 2011) e a construção do corpus tem como base a análise de conteúdo orientada por Bardin (2011) ${ }^{1}$. Como resultado principal, depreende-se que o ethos efetivo vincula-se à noção de empreendedorismo feminino mediante cenas estereotipadas, onde a mulher ainda se encontra em posição periférica.
\end{abstract}

Palavras-chave: empreendedorismo; ethos; cultura; mulheres empreendedoras; imagens de si.

\begin{abstract}
The article deals with the theme of entrepreneurship, especially the ethos of the entrepreneurial woman. It aims to analyse the representation of female entrepreneurship and identify the cultural aspects that are manifested in enunciative scenes and the discursive ethos in discursive material disclosed in the Women Entrepreneurs Network. The discursive analysis is based on the proposal of Maingueneau (1997, 2008a, b, 2011) and the construction of the corpus is based on content analysis guided by Bardin (2011). As a main result, one can deduce that the effective ethos is linked to the notion of female entrepreneurship through stereotyped scenes, where the woman is still in a peripheral position.
\end{abstract}

Keywords: entrepreneurship; ethos; culture; women entrepreneurs; self-images.

\section{Considerações iniciais}

$\mathrm{O}$ artigo trata de questões relativas ao empreendedorismo no mundo contemporâneo, especialmente no que se refere à representação do empreendedorismo feminino no Portal Rede Mulheres Empreendedoras. Pode-se dizer que recentemente as mulheres têm conseguido conquistar mais e novas posições no mercado de trabalho, muitas delas enquanto empreendedoras. Diante disso, percebe-se que o empreendedorismo fe-

\footnotetext{
1 Salienta-se que a opção das autoras pela inclusão de técnicas relativas à análise de conteúdo para construção do corpus deve-se ao volume de dados disponíveis na fonte discursiva consultada. Nesse sentido, tais procedimentos foram importantes para que se pudesse realizar a análise discursiva, fundamentada pelos preceitos de Maingueneau, de modo mais fecundo diante das materialidades disponíveis. Em acordo com Rocha e Deusdará (2005), conduz-se a análise discursiva considerando texto e contexto. Assim, busca-se um olhar complementar entre tais pontos de vista.
}

minino é tematizado em diferentes espaços midiáticos e das mais diversas formas, o que implica pontos de vista difusos. Como resultado, tais representações culturais constroem imagens ${ }^{2}$ que se cristalizam na sociedade.

Com base nestas considerações, delineia-se como questão norteadora deste estudo: a representação do empreendedorismo feminino é fundamentada por cenas enunciativas que auxiliam na construção do ethos discursivo e associam-se aos aspectos culturais na sociedade. Este trabalho contribui para o entendimento dos princípios que norteiam a construção da imagem de si, o ethos discursivo, e tem como objetivo analisar a representação do empreendedorismo feminino e identificar os aspectos culturais que se manifestam nas cenas

\footnotetext{
2 As imagens, no nosso estudo, são utilizadas, na perspectiva de Maingueneau (2008), como imagens de si, ou seja, o ethos discursivo.
} 
enunciativas e no ethos discursivo em materialidades discursivas divulgadas no Portal Rede Mulheres Empreendedoras, doravante PRME.

$\mathrm{O}$ embasamento teórico sobre cultura apoia-se em Geertz (2008) e as questões do empreendedorismo são sustentadas por Bruin, Brusch e Welter (2006), Alh (2002) e Dornelas (2012). A condução metodológica realiza-se em duas etapas, a começar pela estratégia de Análise de Conteúdo (BARDIN, 2011) para a elaboração de um mapeamento temático abordado pelo portal. Com base nesse levantamento, selecionam-se cinco materialidades representativas para a análise do discurso e a identificação das representações do empreendedorismo feminino. A condução da análise discursiva fundamenta-se na perspectiva da escola francesa, em especial, na proposta de Dominique Maingueneau (2008a, b).

Trata-se de uma pesquisa aplicada, com abordagem qualitativa, pautada em objetivos de ordem exploratória e descritiva. Considera-se uma pesquisa de cunho bibliográfico e documental, descrita como um estudo de caso. As análises realizadas nesta pesquisa encaminham o diálogo à compreensão da cultura como um construto social que contempla discussões sobre o empreendedorismo feminino, assentadas, ainda, em estereótipos que suscitam esforços individuais e coletivos na busca da igualdade de direitos femininos nos ambientes socioprofissionais.

As seções do artigo estão assim dispostas: primeiramente, um espaço dedicado à reflexão de questões sobre a cultura e o empreendedorismo feminino. $\mathrm{Na}$ sequência, apresenta-se a compreensão das noções de cenografia e de ethos discursivo. Prossegue-se com a abordagem metodológica, seguida da seção de análise e resultados do estudo de caso. Por fim, apresentam-se as questões relativas à cultura e ao empreendedorismo feminino.

\section{A cultura e o empreendedorismo feminino em cena}

A complexidade dos estudos sobre a cultura oferece aos pesquisadores um leque de possibilidades compreensivas acerca de tal conceito. A manifestação da cultura tem vínculos com contextos sócio-históricos, mantendo recíprocas as relações com as sociedades de que participa. As manifestações culturais estão repletas de conteúdo e de significados que instigam a produção de sentidos nos diversos espaços de convívio coletivo. Neste processo de construção social, o empreendedorismo feminino encontra lugar como uma forma de inserção da mulher no meio laboral.

Assim, pode-se dizer que a cultura possibilita o compartilhamento de significados por meio da linguagem, sendo possível dar significado e sentido a todas às coisas.
Todos os significados são produzidos e partilhados pela linguagem. O ser humano nesse movimento é "[...] um animal amarrado à teia de significados que ele mesmo teceu, assumo a cultura como sendo essas teias e a sua análise; portanto, não como uma ciência experimental em busca de leis, mas como uma ciência interpretativa à procura do significado." (GEERTZ, 2008, p.4).

Canclini (1998) entende a cultura como um processo em constante transformação, que contribui para uma conduta de mobilidade e de ação. Segundo esse autor, todas as culturas têm formas próprias de organização e características intrínsecas e, embora possam parecer estranhas, devem ser respeitadas. Santos (1996, p. 79) salienta que "a discussão de cultura sempre remete ao processo, à experiência histórica. Não há sentido em ver a cultura como um sistema fechado". Assim, os processos culturais vão se transformando no tempo e com eles, as formas de relações humanas e de trabalho.

Dado o interesse pelas questões do empreendedorismo feminino, no intuito de entender como este fenômeno tem ganhado espaço em nossa cultura, pode-se dizer que o empreendedorismo começou a ser propagado no mundo a partir do século XVII e implica aquele, ou aquela, que assume riscos ao começar algo novo (DORNELLAS, 2012). No século XX, Joseph Schumpeter (1982), um dos autores mais relevantes neste campo, definiu como empreendedor aquele que reforma ou revoluciona algo (termo destruição criativa). Peter Drucker (2016), considerado o pai da administração, avalia que o empreendedor é aquele que aproveita as oportunidades para gerar mudanças.

Diante dessas ponderações, nota-se que o processo histórico evidencia os diversos conceitos sobre o que é ser um empreendedor. Salienta-se, ainda, que são pontos de vista atrelados aos processos culturais e às práticas sociais elaboradas pelos agentes em determinados contextos históricos. Essa dependência espaço-temporal é também reconhecida por Dolabela (1999) que ressalta duas como as principais abordagens sobre empreendedorismo: i) abordagem econômica; ii) abordagem comportamental. No mesmo sentido, Dornellas (2012) explica que para os economistas o empreendedorismo está relacionado à inovação, enquanto que para os comportamentalistas o enfoque está em aspectos atitudinais, com a criatividade e a intuição.

Em relatório divulgado em 2017, o Global Entrepreneurship Monitor (GEM) destaca que o empreendedorismo surge por dois critérios básicos de existência: o empreendedorismo por necessidade e o empreendedorismo por oportunidade. No Brasil, o maior índice de empreendedorismo é por necessidade (GEM, 2017). De acordo com Hisrich, Peters e Shepherd (2009, p.33), "o papel do empreendedorismo no desenvolvi- 
mento econômico envolve mais do que apenas o aumento de produção e renda per capita; envolve iniciar e construir mudanças na estrutura do negócio e da sociedade". A partir das considerações apresentadas até o momento, percebe-se que os processos culturais intervêm no processo de construção simbólica sobre o empreendedorismo, dando formas aos novos contextos laborais e às novas relações de trabalho dos agentes sociais.

Nesta perspectiva, embora já se reconhecesse, no início dos anos 1980, em conferências de universidade americanas, a necessidade de investigação a respeito da mulher em atividade empreendedora, foi apenas a partir de 2003 que o empreendedorismo feminino ganhou voz por meio do projeto Diana Project ${ }^{3}$, da Babson College. É notório que, até a década de 1990, muito tenha sido dito sobre o homem empreendedor. Entretanto, com a ampliação da participação da mulher nesse âmbito, tornouse necessário dar destaque às pesquisas que dão voz às empreendedoras mulheres (BRUIN; BRUSH; WELTER, 2006). Os estudos sobre o empreendedorismo feminino auxiliaram na identificação de que, tantos homens quanto mulheres, possuem características empreendedoras, porém a mulher enfrenta maiores dificuldades sociais e culturais para empreender (ALH, 2002).

Assim, encontram-se em elementos culturais, esclarecimentos acerca do papel coadjuvante atribuído à mulher por muitos anos no que tange às instâncias laborais. A busca por uma equidade de gênero, que objetiva o desenvolvimento social das nações (ALH, 2002), sugere $\mathrm{o}$ acesso das mulheres às diversas possibilidades de empregabilidade, antes somente dedicadas aos homens. Tendo em vista estes apontamentos, avança-se à próxima seção que apresenta as noções discursivas que nortearão as análises das materialidades linguísticas do PRME.

\section{As cenas de enunciação e o ethos: as maneiras de dizer e as imagens de si}

As práticas sociais, conforme entendimento sustentado nesta investigação, implicam o processo interpretativo dos indivíduos acerca do mundo que o cerceia. Nesse sentido, compreende-se que é no discurso, por meio da linguagem, que o ser humano constrói suas relações socioprofissionais. A partir disso, acredita-se que os significados fundamentam os processos sociais nos quais

\footnotetext{
3 "Em 1999, Candida Brush, Patricia Greene, Nancy Carter, Elizabeth Gatewood e Myra Hart lançaram o Projeto DIANA para estudar o fenômeno do empreendedorismo feminino nos Estados Unidos. Em 2003, o objetivo da criação da colaboração da DIANA Internacional foi duplo: fornecer uma plataforma para desenvolver, conduzir e partilhar uma agenda de investigação global. Criar uma comunidade internacional de estudiosos dedicados a responder às perguntas sobre mulheres empresárias e empresas orientadas para o crescimento". (PROJECT, 2017, s. p.).
}

foram elaborados. Dessa forma, articulam-se os estudos discursivos na pesquisa, uma vez que é na linguagem que o empreendedorismo feminino é representado e as manifestações culturais são reveladas.

A perspectiva do ato enunciativo perpassa a reflexão sobre o estatuto do enunciador e o destinatário ${ }^{4}$. De acordo com Maingueneau (2008a, p. 87, grifo do autor), “os diversos modos da subjetividade enunciativa dependem igualmente da competência discursiva, sendo que cada discurso, define o estatuto que o enunciador deve atribuir a seu destinatário para legitimar seu dizer". Pode-se dizer, também, que tanto o enunciador quanto o destinatário apoderam-se de um lugar e, nesse espaço, o enunciador projeta uma imagem de si no discurso a partir da qual o legitima (FREITAS, 2011).

$\mathrm{Na}$ enunciação midiática, ou seja, no modo como as mídias representam o empreendedorismo, que a análise discursiva ora proposta repousa. O discurso é linguagem em interação, vinculado às construções de sentido. A partir da cena enunciativa, revela-se a personalidade do enunciador, que se constitui no ethos discursivo. Definem-se as cenas englobante e genérica, além da cenografia ${ }^{5}$, como conceitos que levam àquilo que o discurso cria. Para tanto, consideram-se as figuras do enunciador e do coenunciador, e o todo que emerge da cena de enunciação.

A imagem de si permite a interpretação dos posicionamentos das mídias e as manifestações culturais que emergem desses discursos. Segundo Freitas (2011), não é possível pensar em discurso de modo estanque, mas como um construto de várias dimensões. A Figura 1 ilustra o ethos discursivo e as duplas flechas revelam pontos de interação.

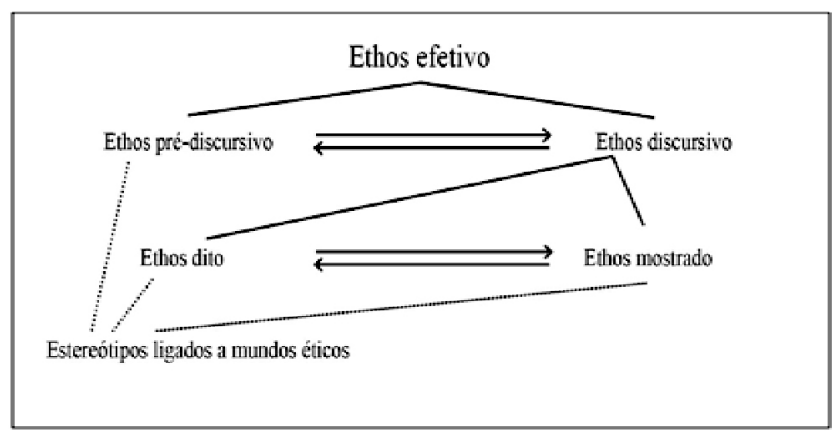

Figura 1. Ethos discursivo

Fonte: Maingueneau (2008a, p. 71).

\footnotetext{
4 O estatuto do enunciador e do destinatário é um dos planos da semântica global, utilizado por Maingueneau (2008b).

5 A cena englobante atribui ao discurso um estatuto pragmático. A cena genérica é a do contrato associado a um gênero, como editorial, sermão, guia turístico, consulta médica etc. (MAINGUENEAU, 2013). Podese dizer que "a cenografia, com o ethos da qual ele participa, implica um processo de enlaçamento: desde sua emergência, a fala é carregada de certo ethos, que, de fato, se valida progressivamente por meio da própria enunciação [...] ela legitima o discurso [...]" (MAINGUENEAU, 2008a, p. 71).
} 
Quando se pensa em ethos discursivo, logo se o vincula à ideia de interação de diversos fatores: ethos pré-discursivo (ethos prévio), ethos discursivo (ethos mostrado), mas também a "fragmentos do texto nos quais o enunciador evoca sua própria enunciação (ethos dito) diretamente - "é um amigo que lhe fala" ou indiretamente, por meio de metáforas ou de alusões a outras cenas de fala, por exemplo" (MAINGUENEAU, 2011, p. 18, grifo e aspas do autor). A diferença entre o ethos dito e o ethos mostrado se inscreve nos limites de uma linha, sendo muito difícil definir uma fronteira cristalina. Assim, o ethos efetivo resulta da interação entre as diversas esferas discursivas. Assim, postas as premissas teóricas, pode-se avançar ao delineamento das questões metodológicas.

\section{Trilhas Metodológicas}

Nesta seção, esclarecem-se os procedimentos adotados para a condução do estudo, a começar pela construção do corpus, sustentada pela análise de conteúdo. Conforme proposto por Bardin (2011), tal proposta analítica demanda a realização de alguns procedimentos a fim de que atenda às expectativas do pesquisador. Nesse sentido, o primeiro passo implica a realização da leitura flutuante, que oportuniza mais clareza e compreensão do objeto de estudo. A partir da definição da coleta de dados em portais da internet, realizou-se uma busca intensa por sites que retratassem a questão do empreendedorismo feminino. Mediante uma pesquisa básica no buscador do Google, com a expressão "sites de empreendedorismo feminino", entre notícias, eventos e programas empresais de incentivo às mulheres empreendedoras, foram identificados sete sites especializados no tema, sendo eles: Mulheres empreendedoras; Rede mulher empreendedora; Voa, Maria; Instituto iaprendi; Consulado da mulher; Meta mulheres empreendedoras transformando ações; Empreendedorismo rosa.

Uma análise minuciosa foi realizada em cada um dos portais mencionados e devido ao tipo de conteúdo divulgado, optou-se pelo PRME, cujo diferencial está na difusão de matérias associadas à gêneros diversos, como dicas, formação, tutorais, discussões, entre outros. Enquanto isso, os demais portais apresentam foco no gênero depoimentos. A partir desta primeira definição, avança-se para o segundo procedimento recomendado por Bardin (2011), que envolve a construção do corpus de pesquisa com base em quatro critérios:

1. Exaustividade: elaborou-se um documento que congrega todos os títulos de matérias publicadas no portal, de acordo com as colunas propostas. Foram catalogados 160 títulos, sendo 22 publicados em mais de uma coluna. Apesar disso, pode-se dizer que o site apresenta bastante conteúdo diferenciado em suas seis colunas. A título de ilustração, o Quadro 1 mostra a relação matérias $\times$ colunas.

Quadro 1. Matérias versus Colunas

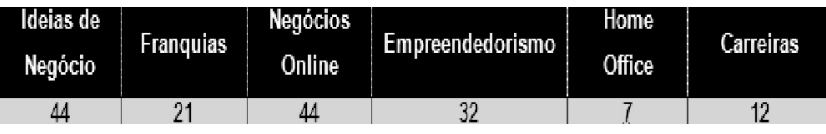

Fonte: elaborado pelas autoras

2. Representatividade: a opção por catalogar todas as matérias divulgadas no portal, mesmo que considerando apenas o título, garante o atendimento ao critério de representatividade, uma vez que permite uma leitura ampla dos conteúdos veiculados, especialmente quanto aos temas, subtemas e gênero dos textos publicados.

3. Homogeneidade: este critério é atendido mediante a seleção de um único portal para coleta de dados, uma vez que garante maior coerência entre as estratégias de exposição do conteúdo e autoria. Salienta-se que a assinatura dos artigos varia entre: i) portal em si; ii) colunistas fixos; e iii) pessoas interessadas em publicar seus textos. Para todos propõem-se regras de construção de conteúdo e realiza-se uma análise prévia a publicação.

4. Pertinência: os conteúdos identificados correspondem ao objetivo estabelecido para o desenvolvimento desta etapa do estudo, que é mapear os principais temas associados ao empreendedorismo e seu direcionamento ao público feminino.

Com base nestes critérios, pode-se avançar com a análise dos conteúdos veiculados no site e produzir, assim, categorias temáticas baseadas nos textos divulgados, para além da organização prévia produzida pelo site. Em uma primeira categorização, chegou-se à oito subtemas: formação (50), alimentação (19), mãe empreendedora (4), negócio de ocasião (20), tecnologia (32), trabalhar em casa (9), estética (16) e moda (11). Percebe-se que o tema mais abordado envolve a formação das empreendedoras, seguido do uso de tecnologias para o trabalho e da criação de empresas baseadas em ocasiões. Entretanto, esse mapeamento, que evidencia uma leitura ampla do site, não reflete plenamente o conteúdo específico de cada coluna proposta.

Tal argumento está calcado na análise dos dados a partir dos gêneros que abarcam os conteúdos publicados no portal. Por exemplo, a coluna Ideias de Negócios contempla o subtema Negócio de Ocasião com mais frequência, enquanto na coluna Negócios Online, o subtema 'Tecnologia' assume relevância. Já nas colunas Franquias, Empreendedorismo e Carreiras, o subtema mais frequente é a 'Formação'. A coluna Home Office 
não apresenta uma categoria de destaque, uma vez que condensa a menor quantidade de artigos. Menciona-se, por fim, a quantidade de materiais veiculados a partir do gênero categorizado pelas autoras: discussão (28), análise (18), tutoriais (52) e dicas (62). Com base neste conjunto de evidências, fundamenta-se a seleção dos conteúdos, cujo estudo será aprofundado por meio da análise discursiva, conforme mostrado no Quadro 2.

Quadro 2. Critérios de Seleção de Conteúdos para Análise

\begin{tabular}{|c|c|c|} 
Coluna & Gễnero & Subtema \\
\hline Ideias de Negócio & Dica & Negócios de Ocasião \\
\hline Franquias & Dica & Formação \\
\hline Negócios Online & Tutoriais & Tecnologia \\
\hline Empreendedorismo & Discussão & Formação \\
\hline Carreiras & Discussão & Formação \\
\hline
\end{tabular}

Fonte: elaborado pelas autoras.

Conforme mostra o Quadro 2, a seleção dos conteúdos para análise discursiva segue os critérios de gênero mais acionado para cada coluna e o subtema mais frequente entre os gêneros disponíveis. Opta-se pela exclusão da coluna Home Office, uma vez que apresenta pouca quantidade de material, além de ser retratada em outros tópicos. A partir daí são avaliados os textos, e a seleção está nos artigos assinados pelo PRME, visto que, acredita-se, devem seguir um estilo narrativo que permita a identificação dos elementos almejados pela pesquisa.

Isto posto, a análise metodológica desloca-se para as premissas discursivas, onde propõem-se duas categorias de análise: a) Cultura e empreendedorismo feminino: observam-se os aspectos culturais manifestados pela materialidade discursiva, além dos tópicos sobre o empreendedorismo feminino. $\mathrm{O}$ embasamento teórico sobre cultura apoia-se em Geertz (2008) e as questões do empreendedorismo são sustentadas por Bruin, Brusch e Welter (2006), Alh (2002) e Dornelas (2012);

b) Cenas enunciativas e o ethos discursivo: buscase apresentar o ethos discursivo, por meio das cenas enunciativas que PRME elabora pelo seu modo de dizer. A condução da análise discursiva fundamenta-se na perspectiva de Maingueneau (2008a, 2008b).

A Figura 2 apresenta o dispositivo metodológico elaborado para a análise das materialidades discursivas elencadas.

O dispositivo construído, conforme mostra a Figura 2, abaixo, revela os passos seguidos para atender o objetivo do estudo que é compreender a representação do empreendedorismo feminino e os aspectos culturais que se manifestam nas cenas enunciativas e no ethos discursivo evidenciados em materialidades discursivas oriundos do PRME. Analisam-se cinco textos do portal, sendo realizados apontamentos individuais para cada texto. Nas considerações finais, elaboram-se, de forma geral, os resultados relativos às cinco materialidades discursivas. Posto isso, prossegue-se com o artigo.

\section{Análises e Resultados: o Modo de Dizer e as Imagens de Si}

Antes de avançar à análise discursiva das materialidades selecionadas, apresentam-se as informações

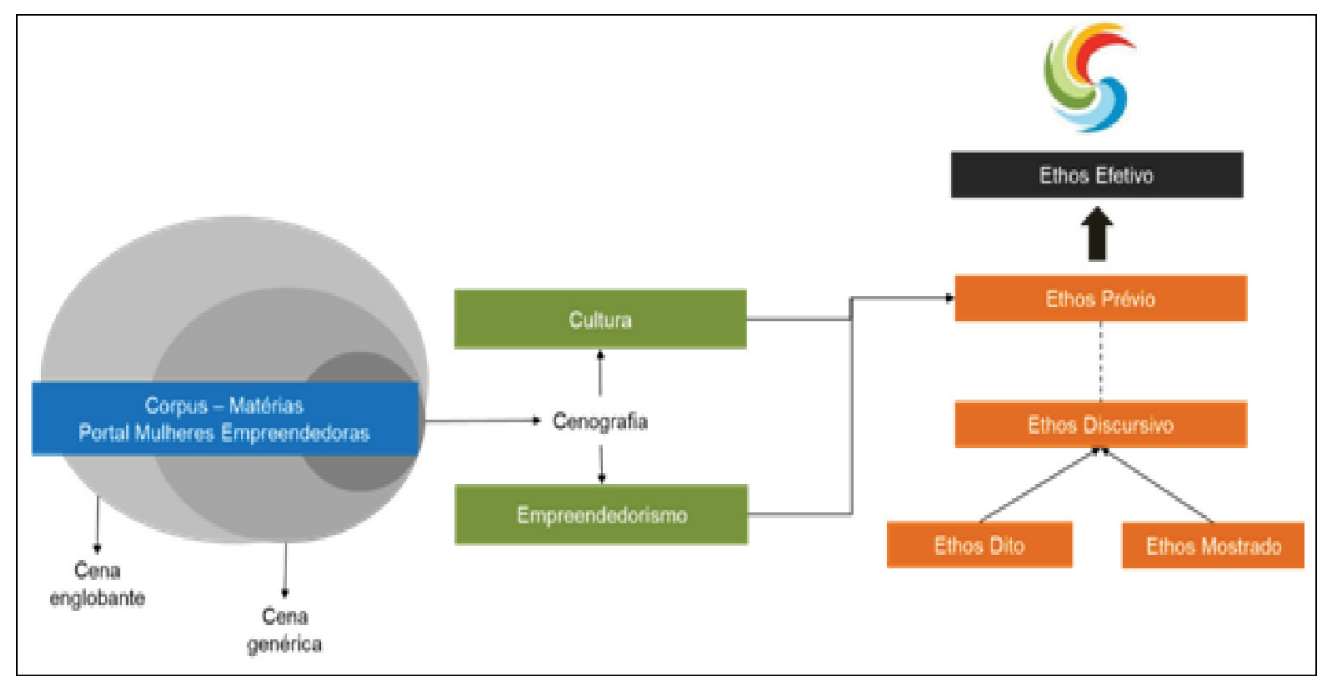

Figura 2. Dispositivo de Análise Fonte: Elaborada pelas autoras. 
acerca do caso em estudo. Trata-se do Portal Rede Mulheres Empreendedoras (PRME) ${ }^{6}$, cujo objetivo é fomentar discussões sobre o empreendedorismo feminino, suas tendências e desafios. O conteúdo é elaborado pela equipe de redatores do portal e também por autoras independentes que enviam seus próprios artigos para publicação. Após a validação dos textos enviados, os editores do portal inserem o conteúdo de acordo com as temáticas de classificação.

Nota-se que as materialidades discursivas do portal, conforme a cena englobante, podem ser caracterizadas como um discurso institucional, onde as temáticas abordadas conduzem aos valores da instituição. A cena genérica (MAINGUENEAU, 2008a) é constituída por gêneros híbridos, visto que se identificam diversas classificações de gêneros, tais como seções de dicas, tutoriais e discussões sobre assuntos diversos. As materialidades eleitas para análise são detalhadas e analisadas, individualmente, conforme propõe a metodologia.

Inicia-se pela materialidade divulgada na coluna Ideia de Negócios, no gênero dicas, cujo tema é "negócios de ocasião", intitulada "Ideias para ganhar dinheiro na Páscoa" "PRME, 2018). Acerca dos aspectos culturais, o discurso aciona elementos relativos ao jeitinho brasileiro (DAMATA, 1986) para superar restrições financeiras, visto que vincula a questão da criatividade para incrementar uma ideia de negócio de ocasião (DORNELLAS, 2012). Em diversos trechos sugere a parceria com uma amiga para ampliação do negócio ou para reunir saberes diferentes em prol de um único negócio. Quanto à categoria empreendedorismo feminino, desde o título já remete ao empreendedorismo por necessidade (GEM, 2017), cujo enfoque está na remuneração monetária para subsistência. $\mathrm{O}$ aspecto relativo a uma proposição sazonal - a Páscoa - também remete à ideia de algo provisório, improvisado e emergencial.

A cenografia encenada pelo enunciador procura criar um contexto de oportunidade e de construção de parceria com o co-enunciador ao enumerar vantagens mediante a adesão às suas dicas. Para tanto, além das ideias, a argumentação é estruturada a fim de construir comprometimento com a leitura, atribuindo à leitora a responsabilidade pelo êxito das ações recomendadas. $O$ ethos prévio assenta-se na proposição de atividades alternativas e que podem ser feitas em casa, o que mantém uma ideia do trabalho doméstico enquanto "bico", de menor importância do que outras atividades. Também trata da possibilidade de que mulher ganhe seu próprio dinheiro sem ter um emprego fora de casa, o que pode

\footnotetext{
6 https://www.mulheresempreendedoras.net.br/.

7 Disponível em: <https://www.mulheresempreendedoras.net.br/ideiaspara-ganhar-dinheiro-na-pascoa/>. Acesso em: 04 fev. 2018.
}

estar relacionado com a educação/cuidado dos filhos, que deve ser feita por ela. Nesse caso, ainda que o discurso mobilize novos sentidos acerca do espaço da mulher na sociedade, a significação que define seu lugar mantém a teia construída socialmente (GEERTZ, 2008).

Quanto ao ethos dito, destaca-se (PRME, 2018, s.p., grifo nosso): "nada melhor do que ganhar um bom dinheiro"; "datas comemorativas são sempre boas opções para aqueles que desejam faturar mais"; "o grande segredo para ser bem-sucedido nesse negócio é oferecer um produto diferenciado, com qualidade e preço competitivo"; "basta ter criatividade e determinação"; "vai depender de sua criatividade, bom gosto e a escolha de produtos com qualidade para montar seu negócio"; "buscar parceria com uma amiga"; "como última ideia desta nossa lista e que por sinal é genial para ganhar dinheiro na Páscoa".

Por fim, o ethos mostrado no primeiro discurso analisado apresenta, por meio da cenografia construída, que a possibilidade de ganhar dinheiro em uma situação pontual, como a Páscoa, garante rendimentos adicionais, mas depende da criatividade e dedicação da mulher. Tratase de uma atividade que atende a um momento e não prevê uma continuidade. Nesse caso, estimula-se uma ação pontual de elaboração de um negócio. O tema também é tratado como algo simples, posto que é mostrado como certeza de retorno financeiro, desde que a mulher esteja efetivamente comprometida com alguma das propostas do artigo. $\mathrm{O}$ empreendedorismo aciona sentidos relativos à improvisação.

O segundo discurso analisado, intitulado "Como escolher o local para abrir uma franquia"8 (PRME, 2018), foi divulgado na coluna Franquias; associase ao gênero dicas e o tema vincula-se à formação. Quanto ao acionamento de elementos culturais, percebese que o enunciador adequa seu tom e corporalidade (MAINGUENEAU, 2011) para envolver intelectualmente seu co-enunciador, que é influenciado a refletir antes de sua tomada de decisão quanto à oportunidade, visto que se trata de um tipo de negócio que demanda um investimento monetário inicial. O tom de seriedade também marca uma complexidade envolvida no tipo de negócio, que demanda muitas avaliações antes de sua realização.

O tom impositivo, como, por exemplo, em "pense da seguinte maneira" e "é fundamental que você observe com cuidado", evidencia o entendimento de que a mulher precisa de ordens para saber o que deve, ou não, fazer quando considera tornar-se empreendedora. A perspectiva do empreendedorismo aqui abordada implica a sua vivência enquanto oportunidade (GEM, 2017): existe a

\footnotetext{
8 Disponível em: <https://www.mulheresempreendedoras.net.br/comoescolher-o-local-para-abrir-uma-franquia/> . Acesso em: 04 fev. 2018.
} 
possibilidade de se investir financeiramente em um tipo de negócio que já está estabelecido no mercado, mas que não está presente em uma determinada localidade, que é analisada pela empreendedora e qualificada como lucrativa.

Para a construção da cenografia, o discurso aciona inicialmente a imagem de um mapa, cuja construção plástica remete ao aplicativo/software Google Maps, um dos mais famosos e utilizados para localização. Essa escolha remete às ideias de direção correta, posto que vale-se de algo já presente e validado pelo co-enunciador (MAINGUENEAU, 2008b). A construção textual baseiase em uma lista de itens que precisam ser considerados: o enunciador deseja posicionar-se como um guru, um facilitador para o co-enunciador. Para isso, propõe um passo-a-passo com dicas que, se seguidas, garantem o êxito da empreendedora.

Relativo ao ethos prévio, compreende-se que o coenunciador não domina o tema abordado, o que justifica um tom escolar, doutrinador, no sentido de definir um passo-a-passo a ser seguido. Como se entende que abrir uma franquia demanda muitas habilidades, trata-se algo muito complexo. Essa perspectiva pode ser observada no ethos dito (grifo nosso): "optar por uma franquia ao invés de iniciar um negócio do zero pode ser mais seguro"; "nada disso poderá ajudar se você escolher a localização errada para o negócio"; "procure não causar conflitos"; "a escolha de um ponto comercial para sua franquia até pode parecer algo simples, mas como você pode reparar existem alguns macetes".

Por fim, acerca da segunda materialidade analisada discursivamente, o ethos mostrado evidencia que devido às múltiplas questões apresentadas neste quesito, o enunciador, o portal, busca formar seu co-enunciador, a empreendedora, para que tenha segurança e êxito no desenvolvimento de seu negócio. Apresenta uma lista de elementos que devem ser considerados para que a mulher não cometa nenhuma falha na sua tomada decisão.

A terceira, das cinco, matérias divulgadas no PRME, intitula-se "como montar uma loja virtual com pouco dinheiro?" (PRME, 2018). Ela foi divulgada na coluna Negócios Online e reconhece-se o gênero tutoriais para o tratamento do tema tecnologia. Baseada na pista discursiva "com o desenvolvimento da tecnologia, montar uma loja virtual se tornou uma tarefa simples", percebe-se que a tecnologia modifica as relações humanas entre o passado, presente e futuro e constrói novos compartilhamentos simbólicos (SANTOS, 1996).

\footnotetext{
9 Disponível em: <https://www.mulheresempreendedoras.net.br/comomontar-uma-loja-virtual-com-pouco-dinheiro/>. Acesso em: 04 fev. 2018.
}

$\mathrm{O}$ empreendedorismo vem associado à tecnologia $\mathrm{e}$ relaciona suas práticas às facilidades do mundo moderno. Acerca do empreendedorismo feminino, a materialidade discursiva sugere a vinculação do empreendedorismo às questões econômicas e financeiras. Associa-se o empreendedorismo a um tipo de negócio que possibilita à mulher sua independência financeira. Utilizado por muitas mulheres para o seu sustento, pode ser considerado um tipo de empreendedorismo por necessidade (GEM, 2017).

O texto produz sua cenografia ao convidar o leitor a montar uma loja virtual e sugerir que tal ação pode ser efetivada com baixo investimento financeiro. As pistas discursivas propõem a realização de um plano de marketing, a fim de diferenciar-se no atendimento, além de delinearem normativas para uma loja de sucesso. O ethos prévio ancora-se no entendimento que as mulheres não têm muito conhecimento sobre como montar uma loja virtual. Salienta-se que o desconhecimento pode ser tanto tecnológico quanto estratégico no tratamento de negócios digitais.

As marcas discursivas implicam o ethos dito enquanto representação do empreendedorismo feminino que busca legitimar a viabilidade dos negócios via internet. $\mathrm{O}$ site convoca os co-enunciadores a aderirem ao discurso mediante as seguintes pistas (PRME, 2018: s. p., grifo nosso): “comece por fazer um plano de negócio"; "definindo objetivos, recursos, metas e todos os pontos necessários para estruturar um e-commerce de sucesso" e busca evidenciar que o empreendedorismo feminino possui um trabalho informativo às mulheres para melhor gerenciar seus negócios.

$\mathrm{O}$ ethos mostrado decorre da cena enunciativa que sugere aos leitores uma receita ideal para quem pensa em montar um e-commerce. O co-enunciador incorpora o discurso, marcado por estereótipos manifestos em chavões, como "um negócio de sucesso". O fiador discursivo, sugere, pela corporalidade e seu caráter descritivo, que as mulheres poderiam empreender melhor se obtiverem mais informações sobre os negócios que desejam começar. $\mathrm{O}$ ethos indica que o empreendedorismo feminino define as mulheres como desprovidas de informações básicas para estruturar negócios.

A quarta materialidade analisada advém da coluna empreendedorismo, constitui-se como gênero de discussão e aborda o tema formação. O título "o momento certo para empreender"10 (PRME, 2018), retrata a "saga empreendedora" e possibilita reflexões sobre a busca pelo empreendedorismo de forma desenfreada. Percebese que, culturalmente, as associações simbólicas que derivam da premissa de se tornar um empreendedor

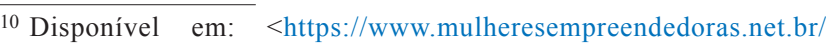
momento-certo-para-empreender/>. Acesso em: 04 fev. 2018.
} 
perpassam, muitas vezes, pelo desejo desenfreado de ter um negócio, sem considerar suas capacidades financeiras e de capacitação.

O empreendedorismo feminino é evidenciado pelas marcas discursivas "é preciso dedicar-se corpo e alma e investir recurso próprios, comprometendo inclusive o padrão de vida e o tempo reservado à família", e sugerem que o empreendedorismo não é algo fácil. Indica cautela na busca pela carreira empreendedora. Percebe-se que o artigo trata do empreendedorismo por necessidade (GEM, 2017), resultando em tomadas de decisão para busca de receita financeira primeiramente.

O texto convida o leitor a refletir sobre o melhor momento de empreender, considerando que a ação empreendedora requer passos lentos e compreensão da totalidade do negócio. Mediante essa cenografia, o ethos prévio está sustentado no entendimento de que o leitor tem muitas dúvidas sobre o momento ideal para iniciar seu empreendimento. Diante disso, imagina-se que o leitor espera que o texto possa contribuir para a sua tomada de decisão. A marca discursiva "qual é o momento certo para empreender" (PRME, 2018, s. p.) manifesta o ethos dito e nota-se que a construção da cena enunciativa revela uma série de questionamentos que os empreendedores têm, quando decidem empreender.

Já a pista "quando a urgência surge" (PRME, 2018, s.p.), indica que o empreendedorismo é utilizado para "apagar incêndios", uma vez que nem sempre o empreendedor está preparado para tal ação. O enunciado "períodos sem ganhos" (PRME, 2018, s.p.) sugere que o empreendedorismo requer disciplina orçamentária e reservas para os períodos iniciais do negócio. Por fim, o ethos mostrado decorre da cena enunciativa que sugere a representação de um empreendedorismo repleto de incertezas e indica que os empreendedores devam ficar atentos a todas as dificuldades que estão por trás do ato de empreender. O tom cauteloso implica o ato de empreender. Busca-se, mediante as marcas discursivas presentes no texto, mostrar os dois lados, ou seja, os pós e os contras acerca do empreendedorismo, sem uma centralidade na questão da mulher.

A última matéria analisada discursivamente foi divulgada na coluna carreiras e trata da formação por meio do gênero discussão. Denominada "A importância do bem-estar para desenvolver um bom trabalho"11 (PRME, 2018), a materialidade discursiva visa "uma visão mais humanista do trabalho" e evoca a premissa da busca por novas maneiras de se relacionar no trabalho. Percebe-se que, culturalmente, o trabalho vem sendo reconhecido como possibilidade de desenvolvimento do ser humano.

\footnotetext{
11 Disponível em: <https://www.mulheresempreendedoras.net.br/ importancia-do-bem-estar-para-desenvolver-um-bom-trabalho/>. Acesso em: 04 fev. 2018
}

A motivação é apresentada como diferencial para o bem-estar no trabalho e no campo social. As pistas enunciadas em "o que motiva as pessoas a se empenharem no trabalho" (PRME, 2018, s.p.) sugerem que o empreendedorismo não deveria ser apenas para atender as demandas financeiras, mas também para que se possa pensar em atividades que atendam ao gosto pessoal e com isso mantenha- se a motivação e a realização das pessoas na realidade laboral. A cenografia do texto convida o leitor a questionar sobre as possibilidades de entendimento do trabalho na contemporaneidade e recomenda a adesão ao pensamento humanizado no que se refere à visão do que representa o trabalho.

O ethos prévio apoia-se na percepção de que o leitor precisa refletir sobre a importância do bem-estar no trabalho, além da sua motivação para desempenhar sua atividade. $\mathrm{O}$ ethos dito apoia essa perspectiva mediante pistas discursivas como "o tema da motivação, satisfação e insatisfação no trabalho, tem sido alvo de estudos e pesquisas teóricas". Elas pretendem a construção de uma cena enunciativa questionadora das noções relativas à motivação e às possibilidades de satisfação que o trabalho proporciona. $\mathrm{O}$ enunciado sugere, ainda, que o empreendedorismo seja uma opção para a busca da motivação no trabalho.

Finalmente, a cena enunciativa evidenciada pelo ethos mostrado preconiza a representação de uma forma de empreender que realize o ser humano. Indica que o trabalho pode ser realizado de forma mais humana e provocadora do bem-estar e realização. O ethos construído indica que o empreendedorismo pode proporcionar bemestar e pode ser considerado como suporte para novas relações no trabalho.

\section{Considerações finais}

Este estudo tematizou sobre as manifestações culturais e a representação do empreendedorismo feminino evidenciados por materialidades discursivas disponíveis no PRME. A investigação revela que, embora o site seja focado em empreendedorismo feminino, não se percebe uma proposta efetiva no tratamento das características e dificuldades enfrentadas por mulheres para desenvolver seu negócio. A caracterização feminina está associada aos tipos de negócio propostos, fundamentada em estereótipos que definem o que é "trabalho de mulher", como o vínculo aos ramos alimentícios e de estética, por exemplo. O tom escolar adotado pelo enunciador também posiciona a leitora como aprendiz, ainda que assuma a ideia de parceria entre enunciador e co-enunciador.

Os conteúdos abordados no material analisado permitem perceber que o seu enfoque está no empreendedorismo feminino por necessidade, ainda que a 
identificação de oportunidades de negócio também seja acionada em alguns textos. Entretanto, a ideia central, em todas as materialidades estudadas, está na dimensão lucrativa monetária, sendo a dimensão da transformação social, por meio de ações empreendedoras, periférica. Tal constatação suscita a necessidade de repensar as estratégias de engajamento referentes ao empreendedorismo, para que seja percebido efetivamente como um modo de desenvolvimento pessoal e, consequentemente, social, para além de uma ideia de situação de transição, provisória.

Com relação ao ethos prévio promove-se uma diferença entre o trabalho em casa (algo em torno da ideia de "bico", visto o volume de negócios sazonais como páscoa, verão, etc.) e o home office (algo mostrado como complexo e que a mulher não domina). Assume-se que a falta de conhecimento da mulher acerca de temas considerados complexos demanda um tom formador e, de certo modo, doutrinador, que tem como intuito a definição de um modo de fazer. Ressalta-se a contradição no que se refere à concepção própria do empreendedorismo feminino enquanto busca de alternativas diferenciadas para efetivação de um negócio.

Quanto ao ethos discursivo, percebe-se, por meio da cenografia construída pelo ethos dito e pelo ethos mostrado, a emersão do empreendedorismo feminino associado à necessidade financeira e de autorrealização. Isso é importante, mas para que haja uma efetiva mudança na representação do empreendedorismo feminino, as indagações discursivas devem buscar análises críticas, interpelando o leitor para discussões que envolvam temáticas, como por exemplo, as relações de poder existentes na sociedade, sugerindo uma abordagem que dê destaque a fatores de subordinação da mulher no trabalho e seu papel neste contexto. Portanto, o ethos efetivo, mediante as cenografias construídas e os ethé ditos e mostrados, percebese um direcionamento da noção de empreendedorismo feminino às cenas estereotipadas da sociedade, onde a mulher ainda se encontra em posição secundária.

\section{Referências}

AHL, Helene.J. The Making of the Female Entrepreneur: A Discourse Analysis of Research Texts on Women's Entrepreneurship. 216f. 2002. Thesis of doctorate degree (Jonkoping International Business School), Jonkoping University, Sweden, 2002. Disponível em: <http://www.divaportal.org/smash/get/diva2:3890/FULLTEXT01.pdf>. Acesso em: 10 fev. 2018.

BRUIN, Anne de; BRUSH, Candida G.; WELTER, Friederike. Introduction to the Special Issue: Towards Building Cumulative Knowledge on Women's Entrepreneurship. Entrepreneurship: Theory and Practice, Baylor University, v. 30, issue 5. p. 485 593, set. 2006. Disponível em: <http://onlinelibrary.wiley.com/ journal/10.1111/(ISSN)1540-6520/issues>. Acesso em: 20 fev. 2018
CANCLINI, Néstor García. Culturas híbridas: estratégias para entrar e sair da modernidade. Tradução Heloísa P. Cintrão e Ana Regina Lessa. 2. ed. São Paulo: Edusp, 1998.

DAMATTA, Roberto. O que faz o brasil, Brasil? Rio de Janeiro: Rocco, 1986.

DOLABELA, Fernando. Oficina do empreendedor. A metodologia de ensino que ajuda a transformar conhecimento em riqueza. São Paulo: Cultura Editores Associados, 1999.

DORNELAS, Jose Carlos Assis. Empreendedorismo: transformando ideias em negócios. Rio de Janeiro-RJ: Campus, 2012.

DRUCKER, Peter Ferdinand. Inovação e espírito empreendedor: práticas e princípios. São Paulo: Cengage, 2016.

FREITAS, Ernani Cesar. Cultura, linguagem e trabalho: comunicação e discurso nas organizações. Desenredo - Revista do Programa de Pós-Graduação em Letras da Universidade de Passo Fundo, v. 7, n. 1, p. 104-126, jan./jun. 2011. Disponível em: <http://www.upf.br/seer/index.php/rd/article/view/1917>. Acesso em: 07 fev. 2018

GEERTZ, Clifford. A interpretação das culturas. 1. ed., 13a reimp. Rio de Janeiro, RJ: Livros Técnicos e Científicos. Editora S.A., 2008.

GEM. Empreendedorismo 2017. Disponível em: <http://www. bibliotecas.sebrae.com.br/chronus/ARQUIVOS CHRONUS/ bds/bds.nsf/70d1237672d36de1ba87890e4cb251cc/\$File/7737. pdf> Acesso: 20 mar. 2018.

HISRICH, Robert D.; PETERS, Michael P.; SHEPHERD, Dean A. Empreendedorismo. 7. ed. Porto Alegre: Bookman, 2009.

MAINGUENEAU, Dominique. Novas tendências em Análise do Discurso. Trad. Freda Indursky. 3. ed. Campinas: Pontes, 1997.

MAINGUENEAU, Dominique. Cenas da enunciação. Organização de Sírio Possenti e Maria Cecilia Pérez de SouzaE-Silva. São Paulo, SP: Parábola Editorial, 2008a.

MAINGUENEAU, Dominique. Gênese dos discursos. Tradução Sírio Possenti. São Paulo, SP: Parábola, Editorial, 2008b.

MAINGUENEAU, Dominique. A propósito do Ethos. In: MOTTA, Ana Raquel; SALGADO, Luciana (Org.). Ethos discursivo. 2. ed. São Paulo: Contexto, 2011. p. 11-32.

MAINGUENEAU, Dominique. Análise de textos de comunicação. 6. ed. São Paulo: Cortez, 2013.

PORTAL MULHERES EMPREENDEDORAS. Disponível em: <https://www.mulheresempreendedoras.net.br/>. Acesso em: 10 fev. 2018

PORTAL REDE MULHERES EMPREENDEDORAS (PRME). Como ganhar dinheiro na Pascoa. Disponível em: $<$ https://www.mulheresempreendedoras.net.br/ideias-paraganhar-dinheiro-na-pascoa/>. Acesso em: 04 fev. 2018.

PORTAL REDE MULHERES EMPREENDEDORAS (PRME). Como escolher o local para abrir uma franquia. Disponível em: <https:/www.mulheresempreendedoras.net.br/ como-escolher-o-local-para-abrir-uma-franquia/>. Acesso em: 04 fev. 2018.

PORTAL REDE MULHERES EMPREENDEDORAS (PRME). Como montar uma loja virtual com pouco dinheiro. Disponível em: $<$ https://www.mulheresempreendedoras.net.br/ como-montar-uma-loja-virtual-com-pouco-dinheiro/>. Acesso em: 04 fev. 2018. 
PORTAL REDE MULHERES EMPREENDEDORAS (PRME). Momento certo para empreender. Disponível em: $<$ https://www.mulheresempreendedoras.net.br/momento-certopara-empreender/>. Acesso em: 04 fev. 2018.

PORTAL REDE MULHERES EMPREENDEDORAS (PRME). A importância do bem-estar para desenvolver um bom trabalho. Disponível em: <https:/www.mulheres empreendedoras.net.br/importancia-do-bem-estar-paradesenvolver-um-bom-trabalho>. Acesso em: 04 fev. 2018.

PROJECT. Diana project. Disponível em: <http://www. babson.edu/Academics/centers/blank-center/global-research/ diana/Pages/home.aspx>. Acesso em: 20 fev. 2017.

ROCHA, Décio; DEUSDARÁ, Bruno. Análise de Conteúdo e Análise do Discurso: aproximações e afastamentos na (re)construção de uma trajetória. In: Revista $A L E A$, v. 7, n. 2, jul.-dez., 2005 p. 305-322.

SANTOS, José Luiz de. O que é cultura. 14. ed. São Paulo: Brasiliense, 1996.

SCHUMPETER, Joseph Alois. Teoria do desenvolvimento econômico: uma investigação sobre lucros, capital, crédito, juro e o ciclo econômico. São Paulo: Abril, 1982.

Recebido: $14 / 05 / 2018$

Aprovado: 14/09/2018

(D) ELIANE DAVILA DOS SANTOS <eliane.d@feevale.br>

Doutoranda, Universidade Feevale, Novo Hamburgo, Rio Grande do Sul, Brasil. (D) GISLENE FeITEN HAUBRICH <gislene@feevale.br>

Doutoranda, Universidade Feevale, Novo Hamburgo, Rio Grande do Sul, Brasil. 